\title{
Lower rim isoxazole-calix[4]arene derivatives as fluorescence sensors for copper(II) ions
}

\author{
Niall J. Maher, Haowen Diao, Justine O’Sullivan, Elisa Fadda, Frances Heaney*, \\ John McGinley ${ }^{* \dagger}$ \\ Department of Chemistry, Maynooth University, Maynooth, Ireland
}

\section{A R T I C L E I N F O}

\section{Article history:}

Received 26 June 2015

Received in revised form 8 October 2015

Accepted 16 October 2015

Available online 19 October 2015

\section{Keywords:}

Calix[4]arene

Isoxazole

NOAC chemistry

Fluorescence

$\mathrm{X}$-ray structure

DFT

\begin{abstract}
A B S T R A C T
Chemosensors designed around a calix[4]arene scaffold, possessing distal isoxazole nuclei as potential recognition sites in conjugation with fluorogenic reporting moieties, have been synthesised and their molecular structures determined by single crystal X-ray analysis. PIC (pyrene-isoxazole-calix[4]arene) and AIC (anthracene-isoxazole-calix[4]arene) are found to be selective and sensitive for the recognition of copper(II) ions over a range of divalent metal ions in a spectrofluorometric study in acetonitrile. Following exposure to copper(II) ions the fluorescence emission intensity of the host was dramatically quenched, in contrast there were no significant shifts to the UV-vis spectra. ${ }^{1} \mathrm{H}$ NMR spectroscopic studies could not provide unambiguous evidence for the mode of ion recognition. Hybrid Density Functional Theory (DFT) calculations for the PIC-copper(II) complex suggests that the metal ion adopts tetrahedral geometry in an acetonitrile solution, while a distorted square pyramidal coordination is also possible in the absence of solvent molecules. Both of these binding conformations cause the disruption of the pyrene-pyrene stacking, consistent with the observed fluorescence quenching.
\end{abstract}

(c) 2015 Elsevier Ltd. All rights reserved.

\section{Introduction}

Metal ion analytes have significant roles in biological and chemical processes and the development of fluorescent sensors for their detection is a rapidly expanding theme in supramolecular chemistry. Calix[4]arene-based metalloreceptors are increasingly valuable in this regard ${ }^{1-4}$ and we have reported several potentially useful derivatives. ${ }^{5-7}$ The development of 'click' chemistry, as described by Sharpless and Meldal, ${ }^{8,9}$ has greatly facilitated the synthesis of lower rim, triazole derivatised calix[4]arenes, many of which have demonstrated metal ion sensing ability. ${ }^{10-18}$ The development of chemosensors for the recognition of copper(II) ions is of considerable interest because of its critical role in chemical and biological systems. A large volume of research has been documented describing different types of sensors for copper ions which utilise UV, near-infrared and fluorescence spectroscopies. ${ }^{19-24}$ In designing systems to detect copper(II) ions, it is imperative that no exogenous copper contaminates the sensor and thus copper-free approaches to functional calix[4]arenes are desirable. We have

\footnotetext{
* Corresponding authors. E-mail addresses: mary.f.heaney@nuim.ie (F. Heaney), john.mcginley@nuim.ie (J. McGinley).

$\dagger$ Current address: Department of Chemistry, University of Copenhagen, DK-2100 Copenhagen $\emptyset$, Denmark.
}

extensively reported on catalyst-free nitrile oxide-alkyne cycloadditions (NOAC) for the formation of isoxazole linked bioconjugates. $^{25-27}$ In this paper, we report the copper-free synthesis, $\mathrm{X}$-ray crystal structures and metal ion sensing abilities of two isoxazole-calix[4]arene derivatives with either pyrene (PIC) or anthracene (AIC) fluorophores.

\section{Results and discussion}

\subsection{Synthesis and characterisation of calix[4]arene de- rivatives PIC and AIC and model compounds PIM and AIM}

The high sensitivity of fluorophores to changes in the microenvironment together with the potential for conjugation between the proposed detecting and responding units motivated a study of the fluoroionophores PIC and AIC, which differ from the more frequently reported calix[4]arene derivatives with a methylene spacer between sensing and reporting motifs. ${ }^{28-30}$ PIC and AIC isoxazolyl-tethered pyrene and anthracene modified calix[4]arenes and model compounds PIM (pyrene-isoxazole-monomer) and AIM (anthracene-isoxazole-monomer) were assembled by catalyst-free NOAC chemistry as detailed in Figs. 1 and 2. tert-Butylphenyl propargyl ether $\mathbf{1}$ was chosen as a model for the dipropargylated calix[4]arene ${ }^{31} \mathbf{4}$ and pyrene and anthracene oximes $\mathbf{2}$ and $\mathbf{3}$ were 


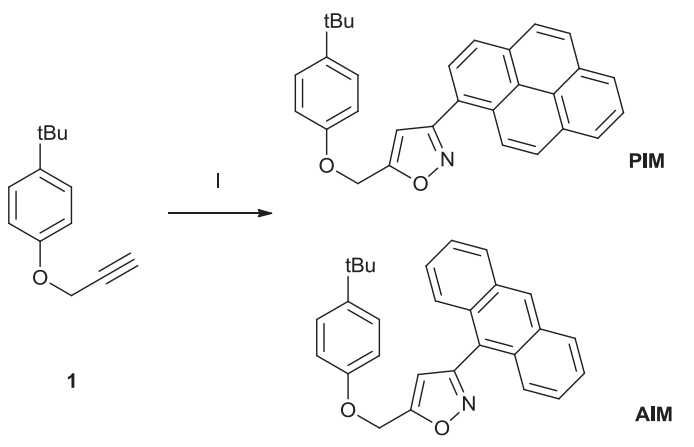

Fig. 1. Synthesis of model compounds PIM (62\%) \& AIM (98\%): i. Chloramine-T, EtOH, reflux, 6 h, 1-pyrene carboxaldehyde oxime (2) or 9-anthracene carbaldehyde oxime (3). rim H-bond facilitated cone conformation, the calix[4]arene methylene bridge protons of PIC and AIC appear as a well resolved pair of $A B$ doublets whilst the tert-butyl groups present as two distinct singlets. ${ }^{36}$ Strong intramolecular $\mathrm{H}$-bonding is indicated by slow $\mathrm{D}_{2} \mathrm{O}$ exchange of the phenolic $\mathrm{OH}$ resonance $\left(\mathrm{CD}_{3} \mathrm{CN} / \mathrm{CDCl}_{3}\right)$, (Supplementary data Figs. 10 and 11).

\subsection{X-ray crystallography}

X-ray analysis indicates that the structures of PIC and AIC, shown in Fig. 3, have much in common. In both cases the asymmetric unit contains one functionalised calix[4]arene molecule with a molecule of solvent of recrystallisation trapped in the upper rim; inclusion of a molecule of $\mathrm{MeCN}^{37-39}$ or $\mathrm{DCM}^{40,41}$ in the upper rim of calix[4]arene scaffolds is known. The crystal data and refinement details for PIC and AIC are included in Table 1. In the solid

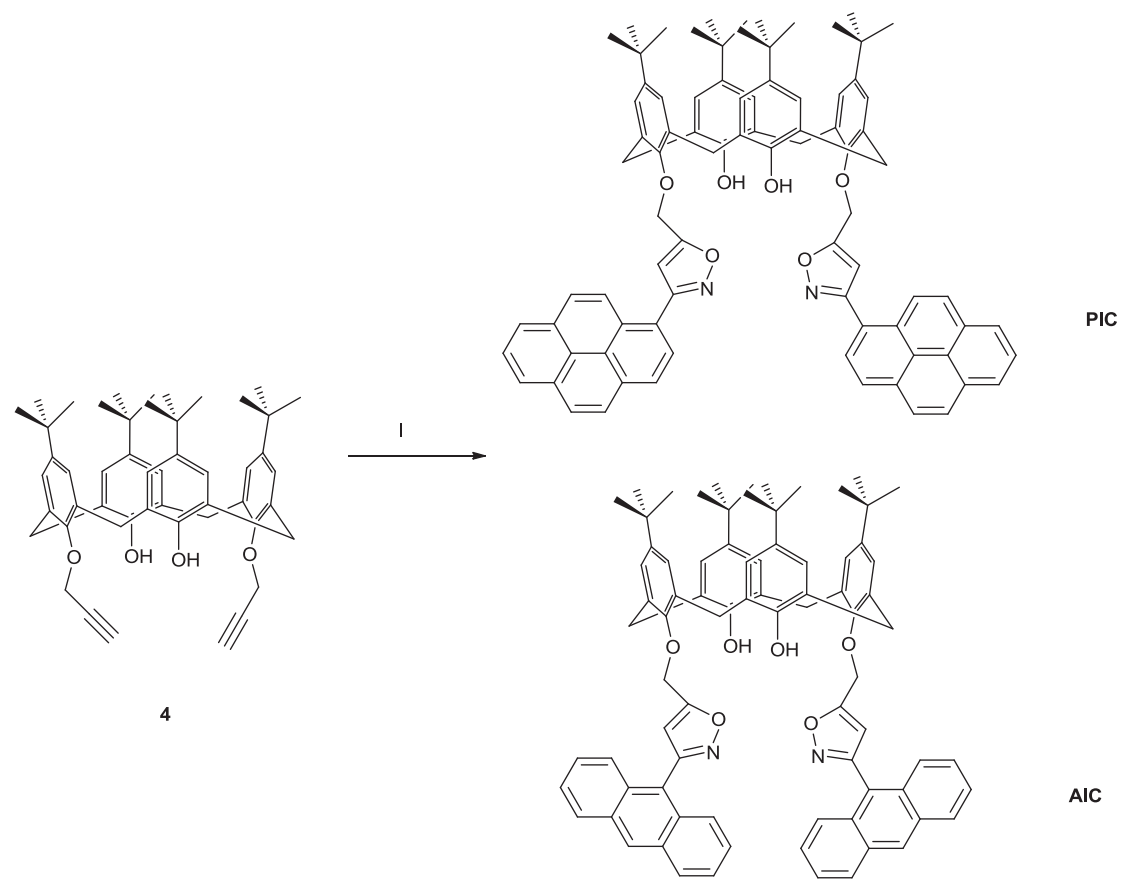

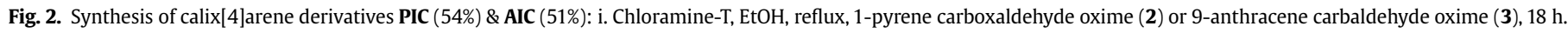

selected as nitrile oxide precursors. The reactive dipoles were obtained in situ following exposure to chloramine-T. ${ }^{32}$ The means of dipole generation is important as it is reported that the alternative hydroximoyl chloride $\mathrm{NEt}_{3}$ protocol requires careful handling in order to obtain the desired anthracene hydroximoyl chloride free from its 10-chloro derivative. ${ }^{33}$ Optimal yields of the model compounds PIM and AIM were obtained following portion-wise addition of an ethanolic solution of the appropriate oxime/chloramine-T couple to a solution of the alkyne in the same solvent (Fig. 1). Successful formation of the pyrene/anthracene-isoxazole-calix[4] arenes, PIC and AIC, required $18 \mathrm{~h}$ reaction time and the pure products were obtained in $\sim 50 \%$ yield following purification by flash column chromatography (Fig. 2). Spectroscopic data supports the regioselectivity of the cycloaddition step. Thus, the resonance of the isoxazole proton as a singlet in the range 6.48-6.97 ppm $\left(\mathrm{CDCl}_{3}\right)$ supports the formation of the isoxazoles as 3,5disubstituted rings. ${ }^{34,35}$ The isoxazole $\mathrm{C}-\mathrm{H}$ resonance of the pyrene substituted calixarene PIC appeared $\sim 0.5 \mathrm{ppm}$ downfield of its 10 -anthracenyl analogue. In keeping with a preference for a lower state, as for the solution structure, the calix[4]arene core of each molecule presents a symmetrical cone, stabilised by intra-annular $\mathrm{H}$-bonds involving the phenolic $\mathrm{OH}$ and the neighbouring ether oxygen atoms. The O...O distances, spanning between $2.74-2.93 \AA$ and 2.75-2.93 $\AA$ for PIC and AIC, respectively, lie within the range of previously published intramolecular $\mathrm{H}$-bonds in related systems. ${ }^{5,72}$ The quality of the AIC crystal is poorer than that of PIC. Whilst the calix[4]arene skeleton is ordered, there is severe disorder in both the upper rim tert-butyl groups and especially the lower rim anthracene units. Similar disorder has previously been observed in related structures with $\mathrm{CHCl}_{3}$ as a guest molecule. ${ }^{43}$ The structure of AIC has much in common with that reported for a closely related triazolomethylanthracene analogue ${ }^{44}$ suggesting a methylene hinge between the five-membered heterocycle and the fluorophoric moiety is not a determining feature of the solid state structure. Within a discrete AIC molecule, the anthracene rings are bent in opposite directions with respect to the calix[4] arene core and are not appropriately aligned for a high degree of face to face overlap, however, intermolecular $\pi$-stacking is a feature 
of the packing diagram (Fig. 14c Supplementary data). The packing diagram of PIC is also dominated by a parallel alignment of pyrene rings from neighbouring molecules. Analysis of the data for PIC provides evidence for a significant intermolecular, $\pi-\pi$ interaction (shown in green) between two pyrene rings within $3.319 \AA$ of each other. In this sense, it deviates from Park's report on a triazolomethylpyrene analogue which proposes intramolecular alignment of the pyrene units. ${ }^{29}$ amide $^{46}$ and triazolomethyl ${ }^{29}$ ligated pyrene calix[4]arene derivatives, following excitation at $\lambda_{\mathrm{ex}} 343 \mathrm{~nm}$ a MeCN solution of PIC $(6 \mu \mathrm{M})$ showed an intense excimer fluorescence (around $498 \mathrm{~nm}$ ) and a relatively weak monomer fluorescence (around 386 \& $406 \mathrm{~nm}$ ) (Fig. 4a). The linearity of the fluorescence response $\left(\lambda_{498} \mathrm{~nm}\right)$ over the concentration range $(1-10 \mu \mathrm{M})$ [Supplementary data Fig. 15b], suggests solution phase intramolecular communication between the pyrene rings gives rise to the excimer emission. a

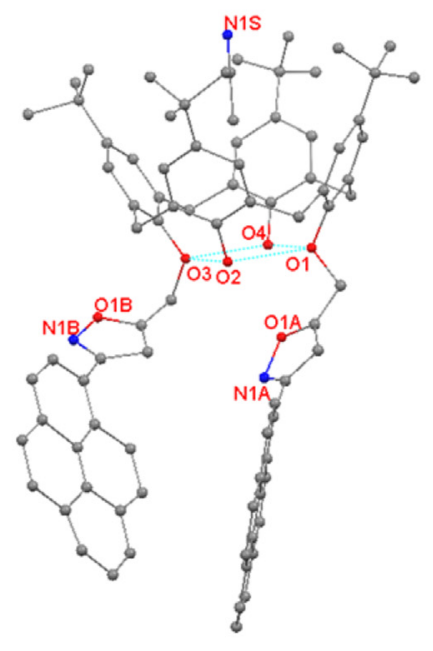

b

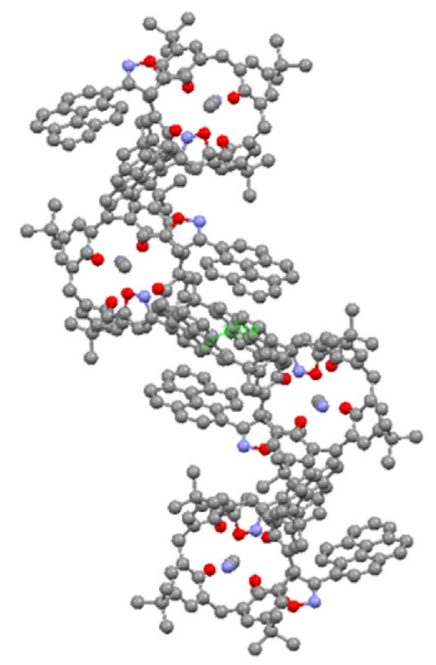

c

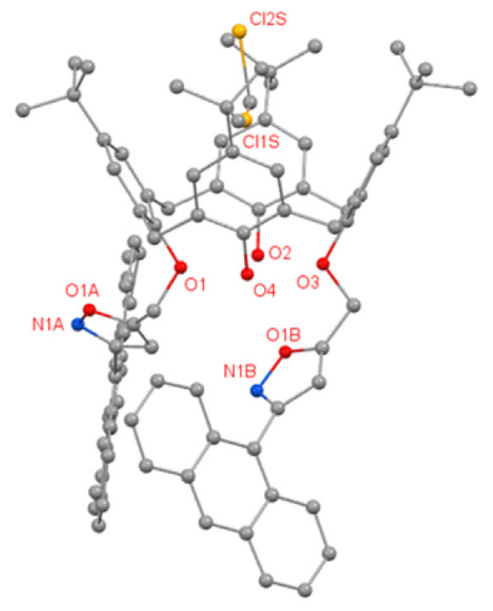

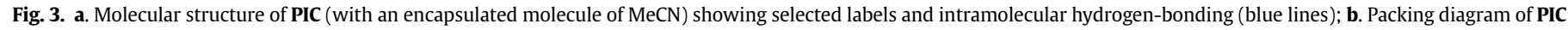

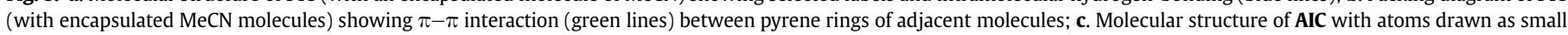
spheres of an arbitrary size and a side-on view of the disordered anthracenyl component. Only one partial occupancy component of DCM disorder is shown.

Table 1

Crystallographic data for ligands PIC and AIC

\begin{tabular}{lll} 
& PIC & AIC \\
\hline Formula & $\mathrm{C}_{86} \mathrm{H}_{85} \mathrm{~N}_{3} \mathrm{O}_{6}$ & $\mathrm{C}_{84} \mathrm{H}_{90} \mathrm{~N}_{2} \mathrm{O}_{8} \mathrm{Cl}$ \\
$\mathrm{M} / \mathrm{g} \mathrm{mol}^{-1}$ & 1256.67 & 1291.03 \\
Crystal system & Monoclinic & Triclinic \\
Space group & $\mathrm{P} 2{ }_{1} / \mathrm{c}$ & $\mathrm{P}-1(\mathrm{No} .2)$ \\
$\mathrm{T} / \mathrm{K}$ & $294(2)$ & $294(2)$ \\
$\mathrm{a} / \AA$ & $27.0042(4)$ & $12.0845(5)$ \\
$\mathrm{b} / \AA$ & $12.6046(2)$ & $13.2176(6)$ \\
$\mathrm{c} / \AA$ & $22.2558(3)$ & $24.5563(8)$ \\
$\alpha{ }^{\circ}$ & 90 & $95.318(3)$ \\
$\beta /{ }^{\circ}$ & $112.002(2)$ & $90.475(3)$ \\
$\gamma /{ }^{\circ}$ & 90 & $96.348(3)$ \\
$\mathrm{V} / \AA^{3}$ & $7023.65(18)$ & $3880.8(3)$ \\
$\mathrm{Z}$ & 4 & 2 \\
$\mathrm{D}_{\mathrm{c}} / \mathrm{g}$ cm & \\
Reflections collected & 1.188 & 1.105 \\
Unique reflections & 22,012 & 27,274 \\
$R_{\text {int }}$ & 11,318 & 15,211 \\
Obs. reflections $[\mathrm{I}>2 \sigma(\mathrm{I})]$ & 0.019 & 0.034 \\
No. of parameters & 7792 & 7063 \\
No. of restraints & 872 & 985 \\
$\mathrm{R} 1[I>2 \sigma 1]$ & 0 & 227 \\
wR2 (all data) & 0.121 & 0.117 \\
GoF & 0.361 & 0.397 \\
\hline & 2.24 & 1.16 \\
\hline & &
\end{tabular}

\subsection{Fluorescence spectroscopy}

The potential of PIC and AIC, as well as model compounds PIM and AIM, to sense metal ions was studied by fluorescence, UV-vis, EPR and ${ }^{1} \mathrm{H}$ NMR spectroscopies, as well as by a theoretical approach. As previously noted for lower rim functionalised ester, ${ }^{45}$
In response to excitation at $\sim 274 \mathrm{~nm}$, a solution of the model compound PIM ( $6 \mu \mathrm{M}, \mathrm{MeCN})$ displayed a strong, monomer emission (386 nm and $406 \mathrm{~nm}$, with a shoulder at $428 \mathrm{~nm}$ ); no excimer emission was evident indicating that intermolecular interaction of the pyrene units is not a feature of the fluorescence spectrum of PIM in MeCN (Fig. 4a). The fluorescence spectra of the anthracene analogues AIC and AIM ( $6 \mu \mathrm{M}, \mathrm{MeCN}, \lambda_{\mathrm{ex}} 364 \mathrm{~nm}$ ), shown in Fig. $4 \mathrm{~b}$, were broad; that of the model compound was structure-less with $\lambda_{\max } \sim 420 \mathrm{~nm}$ whilst structured excimer emission bands at $\sim 420$ and $440 \mathrm{~nm}$ could be deciphered for AIC.

The potential of PIC and AIC and the model compounds PIM or AIM to sense a variety of metal perchlorate salts including mercury(II), nickel(II), zinc(II), cobalt(II), iron(II), lead(II), cadmium(II) and copper(II) was evaluated by their fluorescence behaviour. Neither of the model compounds, PIM or AIM, with one isoxazole ring and one fluorogenic moiety showed a tangible response to the range of metal salts studied (Supplementary data, Figs. 18 and 19). In contrast, the ligands constructed around the calix[4]arene scaffold elicited a dramatic quenching of the fluorescence emission only on exposure to copper perchlorate (Fig. 5). The failure of model compounds, PIM or AIM, to respond spectrofluorometrically to the presence of copper(II) ions intimates that the conformational confines of the calixarene scaffold of PIC and AIC is necessary for the system to deliver the twin requirements of efficient ion complexation and effective reporting of the binding event.

The potential for real-life applications was probed by assessing the sensitivity and selectivity of PIC for copper ions under a range of experimental conditions. A fundamental role for the anion in moderating sensitivity was discovered following an observed increasingly ineffective quenching of the excimer signal in response to copper(II) chloride, nitrate, and acetate salts (100 equiv) (Fig. 6). 
a

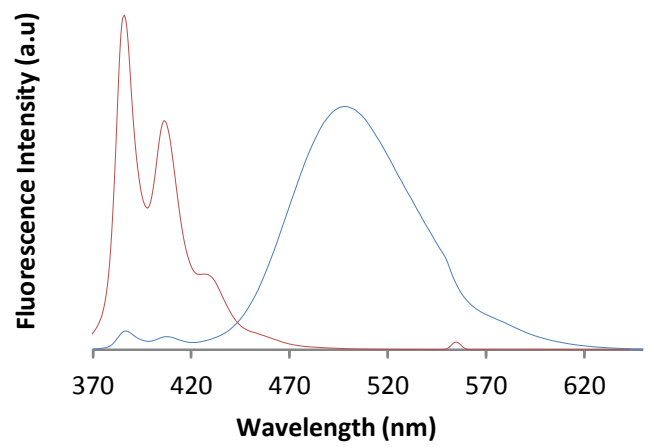

b

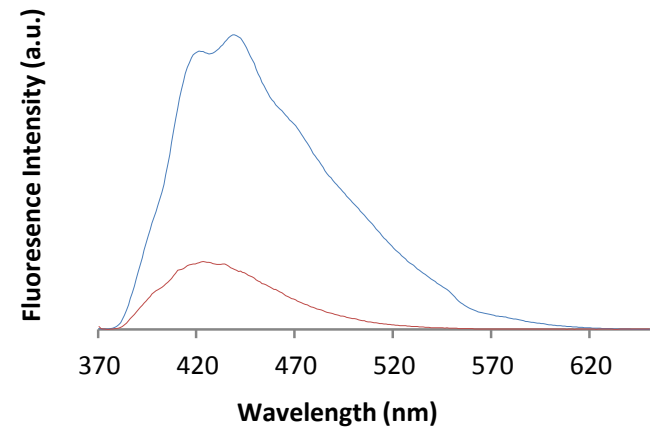

Fig. 4. Fluorescence emission spectra of $\mathbf{L}\left(6 \mu \mathrm{M}\right.$ in MeCN). a. PIC (blue, $\lambda_{\mathrm{ex}} 343 \mathrm{~nm}$ ) and PIM (red, $\lambda_{\mathrm{ex}} 274 \mathrm{~nm}$ ): b. AIC (blue, $\left.\lambda_{\mathrm{ex}} 364 \mathrm{~nm}\right)$ and AIM (red, $\lambda_{\mathrm{ex}} 364 \mathrm{~nm}$ ).

a

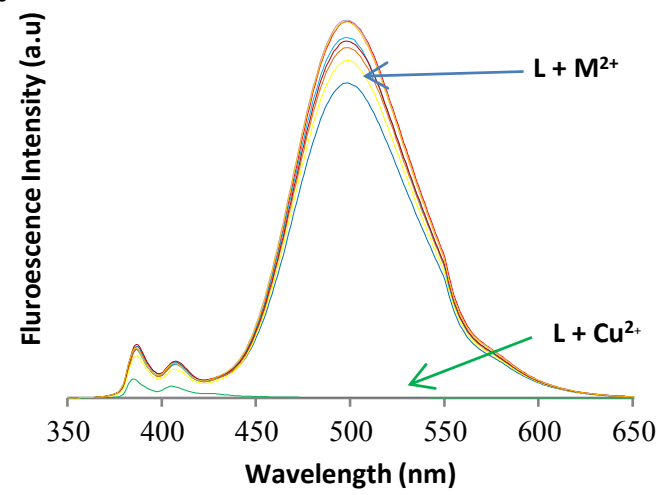

b

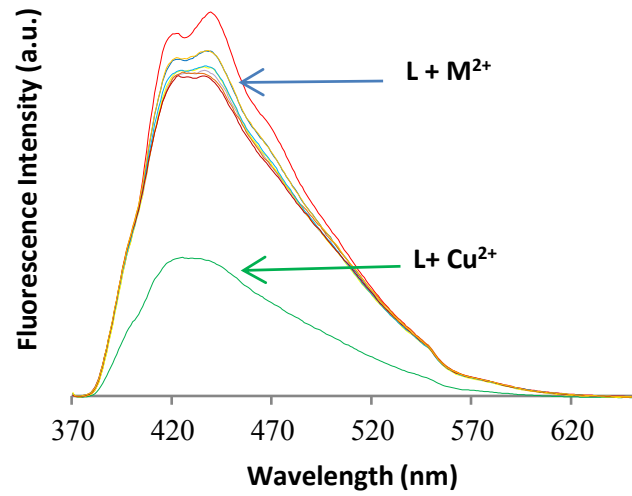

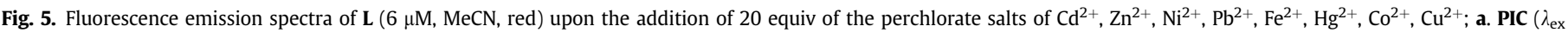
$343 \mathrm{~nm})$ and b. AIC $\left(\lambda_{\mathrm{ex}} 364 \mathrm{~nm}\right)$.

a

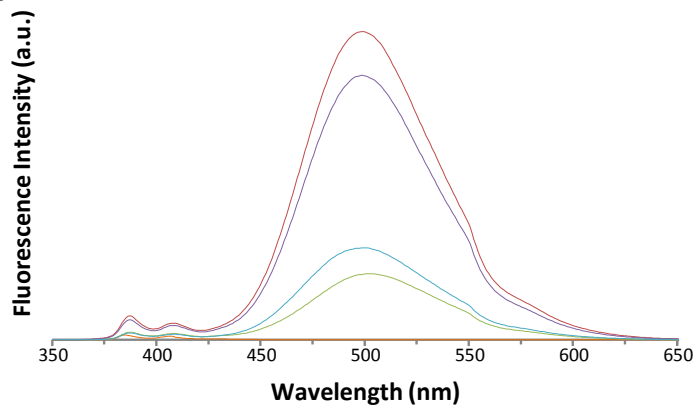

b

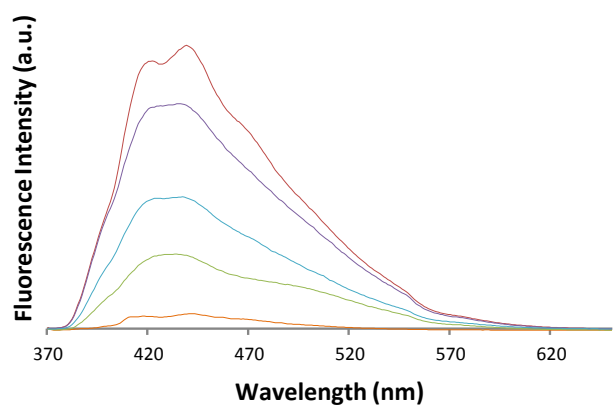

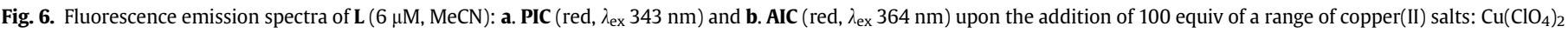
(orange), $\mathrm{CuCl}_{2}$ (green), $\mathrm{Cu}\left(\mathrm{NO}_{3}\right)_{2}$ (blue) and $\mathrm{Cu}\left(\mathrm{CH}_{3} \mathrm{CO}_{2}\right)_{2}$ (purple).

The observed trend parallels the relative dissociation of the salts in $\mathrm{MeCN}$ and the enhanced capacity to detect copper(II) perchlorate is likely a consequence of its existence effectively as a solvent separated ion pair, with the copper cation presenting as $\left[\mathrm{Cu}(\mathrm{MeCN})_{6}\right]^{2+}{ }^{47}$ Indeed, the failure of PIC to respond spectrofluorometrically to copper(II) perchlorate in either EtOH or in $\mathrm{MeOH} / \mathrm{CHCl}_{3}$ (96:4) reinforces the significance of the solvent choice which may have a bearing on salt dissociation and on the architecture of both the free calixarene and its metal ion complex (Supplementary data Fig. 20).
A comparative fluorescence titration study indicates PIC retains the ability to sense copper(II) ions in the presence of other contamination perchlorate salts. Whilst the initial fluorescence intensity of PIC ( $\lambda_{\max } 498 \mathrm{~nm}$ ) on the addition of 20 equiv of mercury(II), nickel(II), zinc(II), cobalt(II), iron(II), lead(II) and cadmium(II) decreased by $0-17 \%$, the subsequent addition of the same number of equivalents of copper perchlorate caused significant further quenching in each case. Thus, it is evident that $\mathbf{L}$ can effectively detect copper in the presence of a variety of contaminating ions (Fig. 7). 


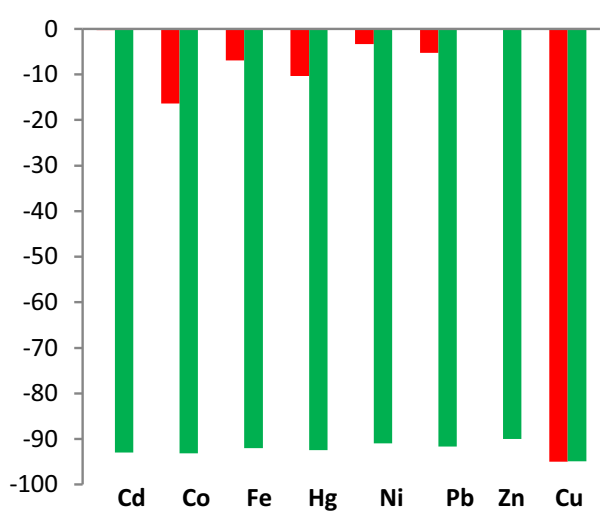

Fig. 7. Percentage change in the intensity of maximum fluorescence emission of PIC $\left(6 \mu \mathrm{M}, \mathrm{MeCN}, \lambda_{\mathrm{ex}} 343 \mathrm{~nm} ; \lambda_{\max } 498 \mathrm{~nm}\right.$ ); Red, upon the addition of 20 equiv of metal perchlorates; Green, upon the further addition of 20 equiv of copper perchlorate to the PIC-metal perchlorate solutions.

To probe the sensing potential of the ligands, the extent of fluorescence quenching of a MeCN solution of $\mathbf{L}(6 \mu \mathrm{M})$ as a function of copper perchlorate concentration was examined. Despite the vast reduction in signal intensity, the spectral features were largely unchanged upon the addition of up to 20 equiv of copper(II) ions. No shift was observed in the wavelength of maximum fluorescence emission for either $\mathbf{L}$, and for PIC quenching of both monomer and excimer bands was apparent (Fig. 8). In the presence of 10 equiv of copper(II) ions, the extent of quenching of

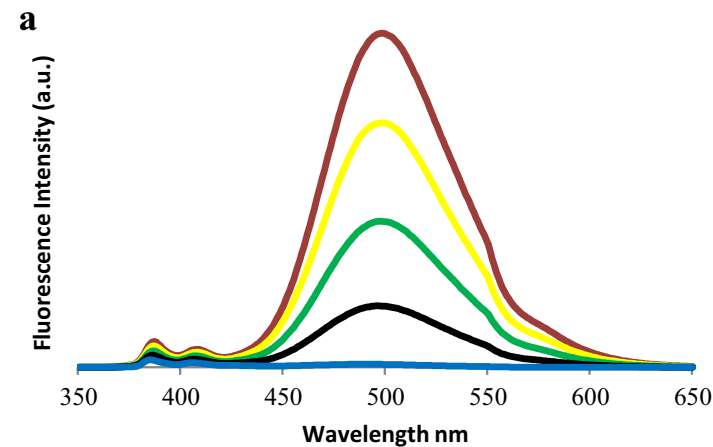

fluorescence emission was high, 65\% and 85\% for AIC and PIC, respectively. Virtually complete quenching of the excimer signal of PIC follows titration of 20 equiv of copper(II) perchlorate (Fig. 8), demonstrating a superior sensitivity with respect to AIC and the related 9-chloroanthracen-1-yl ${ }^{33}$ and 1-naphthyl ${ }^{48}$ analogues. The observed quenching is reconcilable with a chelation-induced change to the spatial configuration of the reporting units diminishing the opportunity for intramolecular communication between the distal pyrene/anthracene units. It is also compatible with a chelation enhanced $\pi$-cation interaction between the polycyclic aromatic rings and the copper(II) ion. The reduction in monomer emission may be accounted for both by the heavy metal ion effect and by reverse PET from the $\pi$-electron fluorophores to the isoxazole nuclei which may have become electron deficient following metal complexation.

The stoichiometry of binding of copper(II) ions with $\mathbf{L}$ was determined by the method of continuous variation and Job plots ${ }^{49}$ constructed. The total concentration of host plus guest was held at $6.0 \mu \mathrm{M}$ with a continuous variable molar concentration of L:guest. For both PIC and AIC the maximum fluorescence change was observed when the molar fraction of L:copper(II) was 0.5 suggesting the formation of 1:1 metal complexes (Fig. 9). The detection limit (DL) of PIC and of AIC for copper(II) was determined, respectively, to be $2.19 \times 10^{-7}$ and $4.87 \times 10^{-6} \mathrm{M}$, using the formula $\mathrm{DL}=\mathrm{K}^{*} \mathrm{SD} 1 / \mathrm{S},{ }^{50}$ where $K=2$ or 3 (we take 2 in this case), SD1 is the standard deviation of the host solution at $6 \mu \mathrm{M}$, and $\mathrm{S}$ is the absolute value of the slope of the calibration plot of $\mathbf{L}(6 \mu \mathrm{M})$ with varying equivalents of copper(II) (0.2-2 equiv) (Supplementary data, Fig. 21).

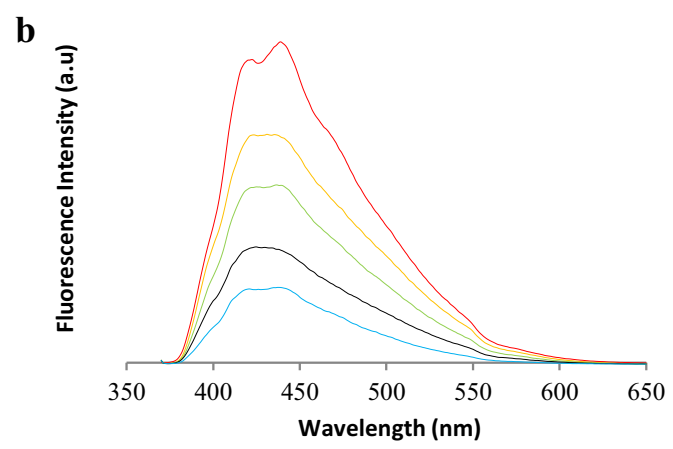

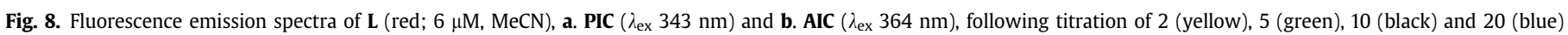
equivalents of $\mathrm{Cu}\left(\mathrm{ClO}_{4}\right)_{2}$ to the host solutions.
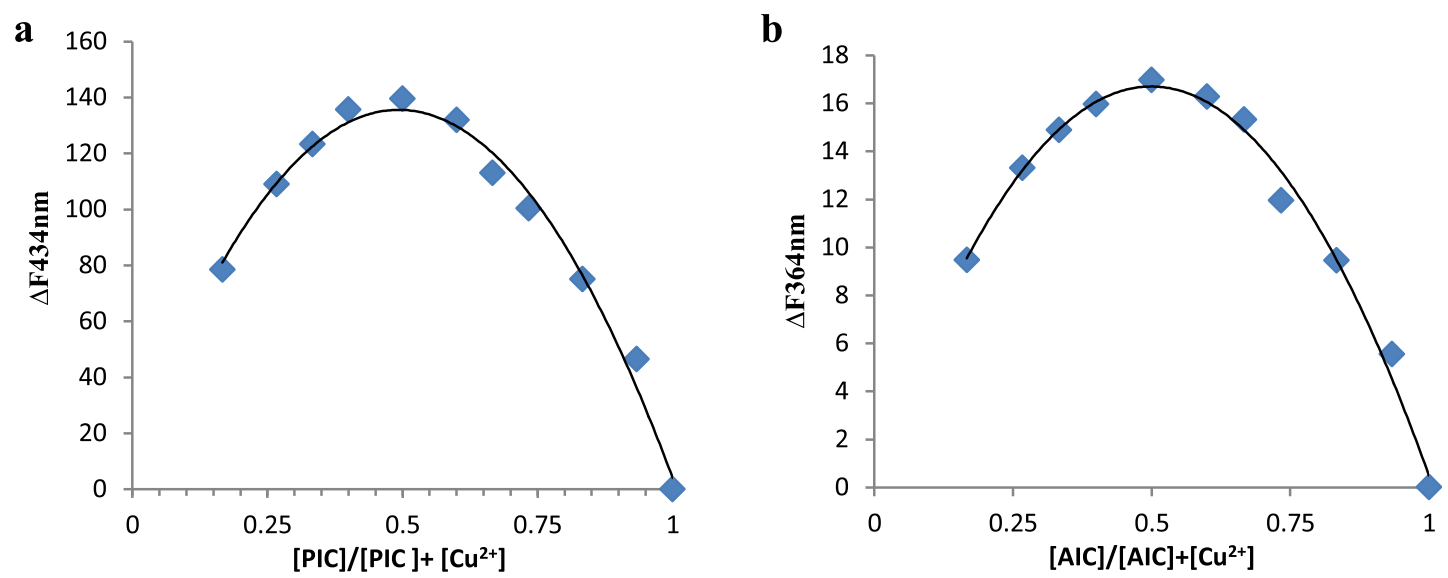

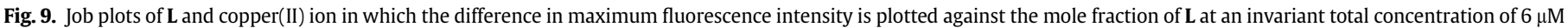
in MeCN; a. PIC ( $\left.\lambda_{\mathrm{ex}} 343 \mathrm{~nm} ; \lambda_{\max } 498 \mathrm{~nm}\right)$ and b. AIC $\left(\lambda_{\mathrm{ex}} 364 \mathrm{~nm} ; \lambda_{\max } 439 \mathrm{~nm}\right)$. 
Association constants of $\sim 4.5 \times 10^{4} \mathrm{M}^{-1}$ and $\sim 2.9 \times 10^{4} \mathrm{M}^{-1}$ were derived for PIC and AIC, respectively, with copper(II) perchlorate following from fluorescence titration experiments in $\mathrm{MeCN}$ and data analysis by the Stern-Volmer approach. Thus, for a $6 \mu \mathrm{M}$ solution of the host in $\mathrm{CH}_{3} \mathrm{CN}$, the ratio of fluorescence intensity, $\mathrm{I}_{0} / \mathrm{I}$ (at $498 \mathrm{~nm}$ for PIC and $425 \mathrm{~nm}$ for AIC) was plotted against the guest concentration, the slope of this straight line graph gives the association constant (Supplementary data Figs. 22a and 23). Analysis of the PIC copper perchlorate titration data by the Benesi-Hildebrand $^{51}$ method proposes $\mathrm{K}_{\mathrm{a}} \sim 4.7 \times 10^{4} \mathrm{M}^{-1}$ (Supplementary data Fig. 22b). The association constant determined for copper(II) and PIC is higher than that calculated for AIC and that reported for the chloroanthracenyl analogue. ${ }^{33}$ It is $\sim 20$ times that of a related structure with isoxazolenaphthyl groups (but without the upper rim tert-butyl groups). ${ }^{48}$ It is thus tempting to propose a relationship between the extent of the $\pi$ electron density of the pendant polycyclic aromatic units and the calculated association constant. Thus, the aryl units of the hosts may be functional not only for fluorogenic communication but also, through $\pi$-electron back-bonding, play a role in guest binding.

\subsection{UV/vis spectroscopy}

In order to evaluate the chromogenic potential of the ligands PIC and AIC, a study of their UV/vis spectra in the presence and absence of copper(II) ions was undertaken. PIC showed a strong absorption band at $350 \mathrm{~nm}$ in MeCN whilst AIC shows the characteristic features of the anthracene chromophore (Fig. 10). Neither ligand showed any shift in the wavelength of maximum absorption upon titration with up to 20 equiv of copper(II) perchlorate. Neither was there any additional absorption band in the region of $430 \mathrm{~nm}$ ruling out the copper(I) generating redox chemistry suggested for related systems. $^{18,33,48}$ Thus, the complexation of $\mathbf{L}$ with copper(II) ions in $\mathrm{MeCN}$ has no chromogenic signature (see Fig. 11). was repeated with PIC or AIC in $\mathrm{MeCN} / \mathrm{CHCl}_{3}$ (3:1) in the presence of up to 5 equiv of copper perchlorate either at room temperature or as a frozen glass at liquid nitrogen temperature. EPR titration studies also failed to support the involvement of a copper(I) species. In a manner similar to that described by Rao and co-workers for related compounds, ${ }^{18}$ varying amounts of a solution of $\mathbf{L}$ (PIC or AIC, $10 \mathrm{mM}, \mathrm{MeCN} / \mathrm{CHCl}_{3}$ 3:1) was added to a copper(II) perchlorate solution $(10 \mathrm{mM}, \mathrm{MeCN})$ at room temperature until a 1:1 equivalence mixture was achieved. In a second study the reverse approach was adopted and the 1:1 equivalence solution was arrived at by adding increasing volumes of the copper perchlorate solution to the L solution. For both PIC and AIC, the final pattern of signals in the EPR spectra was independent of the direction of the titration experiment. Thus, the data from the first set of titrations showed no obvious change in the position or shape of the signal on going from a $\mathrm{Cu}\left(\mathrm{ClO}_{4}\right)_{2}$ solution to a $\mathrm{Cu}\left(\mathrm{ClO}_{4}\right)_{2}$ : $\mathbf{L}$ solution. The spectra for the 1:0.5 equiv sample lie on top of each other, whilst the $1: 1$ equivalence sample shows slight signal broadening, (Supplementary data, Fig. 25a, c). The data suggests no change to the geometry about the copper(II) ion in going from the acetonitrile solution of the perchlorate salt to the $\mathrm{Cu}\left(\mathrm{ClO}_{4}\right)_{2}: \mathbf{L}$ acetonitrile solution. In the case of the free salt solution, the ion presumably adopts octahedral geometry and is surrounded by six nitrogen donor solvent molecules. We postulate that in the presence of $\mathbf{L}$ the copper ion remains hexacoordinate with two of the six coordination sites occupied by the nitrogen atoms of the two isoxazole moieties of PIC/AIC and the remaining four taken up with acetonitrile molecules. The data from the second study, in which increasing amounts of the perchlorate salt are added to the ligand solution, show an increase in signal intensity in line with an increasing quantity of copper perchlorate in the analysis solution, no change to the position or shape of the signals was observed (Supplementary data, Fig. 25b, d). The consistency of the line shape of the copper EPR signal throughout the range is suggestive of instantaneous sequestering of copper ions in
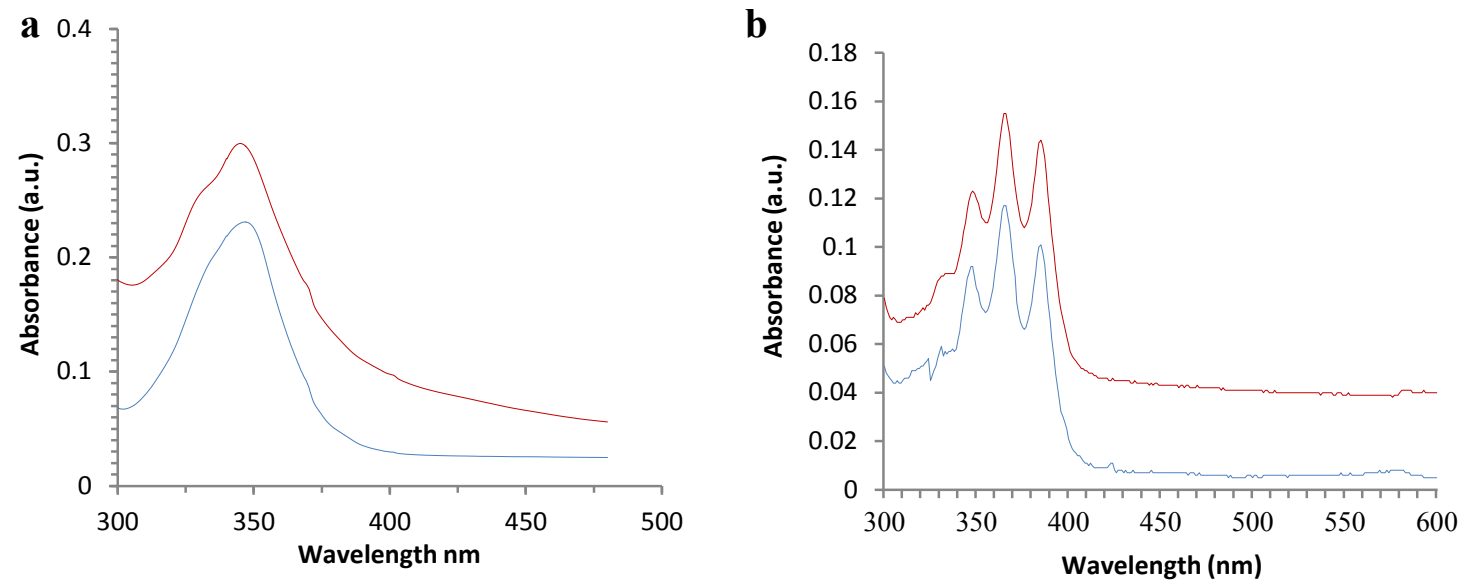

Fig. 10. UV/vis spectra (MeCN), of $\mathbf{L}$ (blue) and $\mathbf{L}+\mathrm{Cu}\left(\mathrm{ClO}_{4}\right)_{2}$ (red). a. PIC; b. AIC: $\mathbf{L}, 6 \mu \mathrm{M} ; \mathrm{Cu}\left(\mathrm{ClO}_{4}\right)_{2} 120 \mu \mathrm{M}$, (20 equiv).

\subsection{EPR spectroscopy}

The autoreduction of copper(II) by the phenolic moieties of the calix[4]arene scaffolds was further considered unlikely following analysis of EPR spectroscopic data gathered for PIC and AIC both in the presence and absence of copper perchlorate. As expected, no signal was observed in the EPR spectrum of PIC or AIC recorded at room temperature either as solid samples or as solutions in $\mathrm{MeCN} /$ $\mathrm{CHCl}_{3}$ (3:1) (Supplementary data, Fig. 24). Neither was there any evidence for the existence of a radical species when the experiment the favoured geometry by both PIC or AIC. This characteristic contrasts with Rao's observations and points to a more favourable copper(II) binding pocket within PIC and AIC than that provided by the calix[4]arene-triazole-benzimidazole system. ${ }^{18}$

\section{6. ${ }^{1}$ H NMR spectroscopy}

A ${ }^{1} \mathrm{H}$ NMR spectroscopic study was undertaken in an effort to uncover details of the copper(II) binding pocket within PIC and AIC. Titrations of $\mathbf{L}$, and of the model compound PIM, with both copper 
$\mathbf{a}$

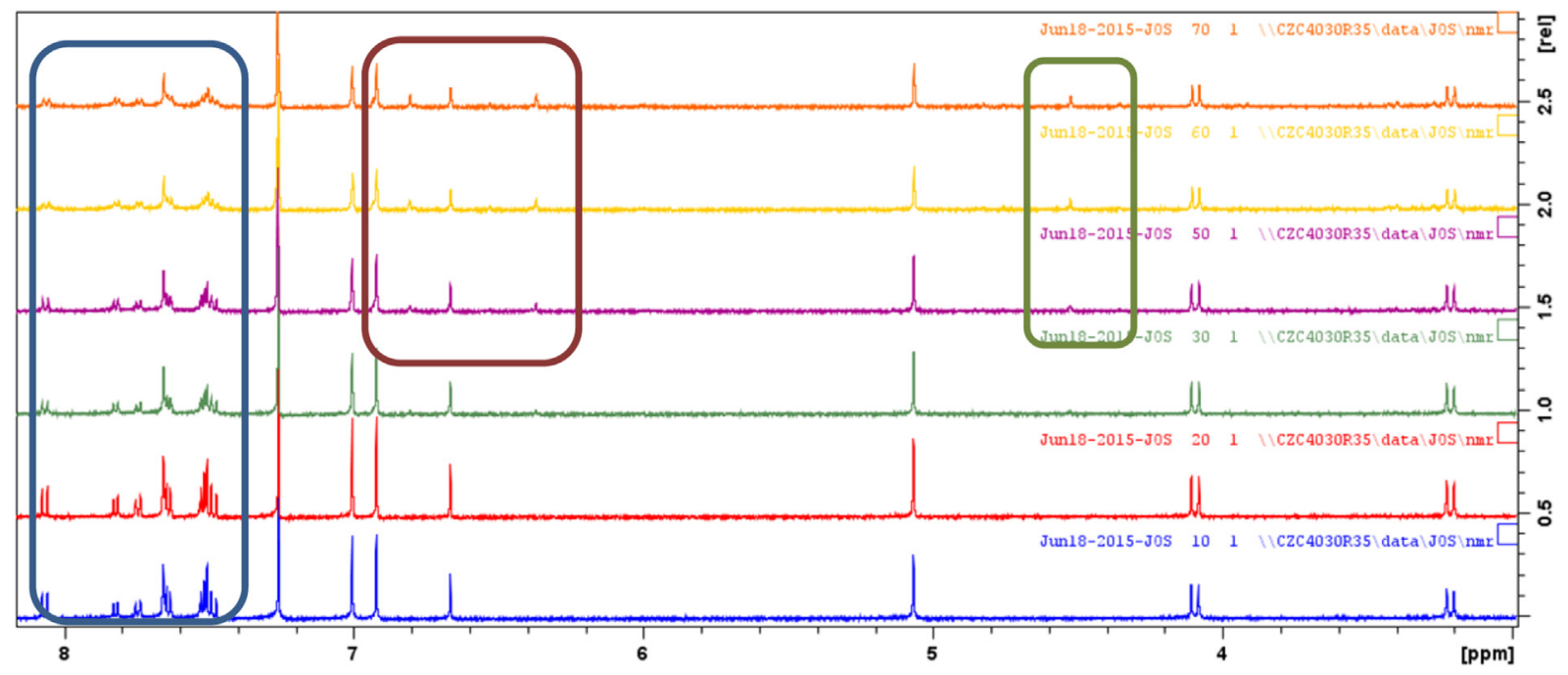

b

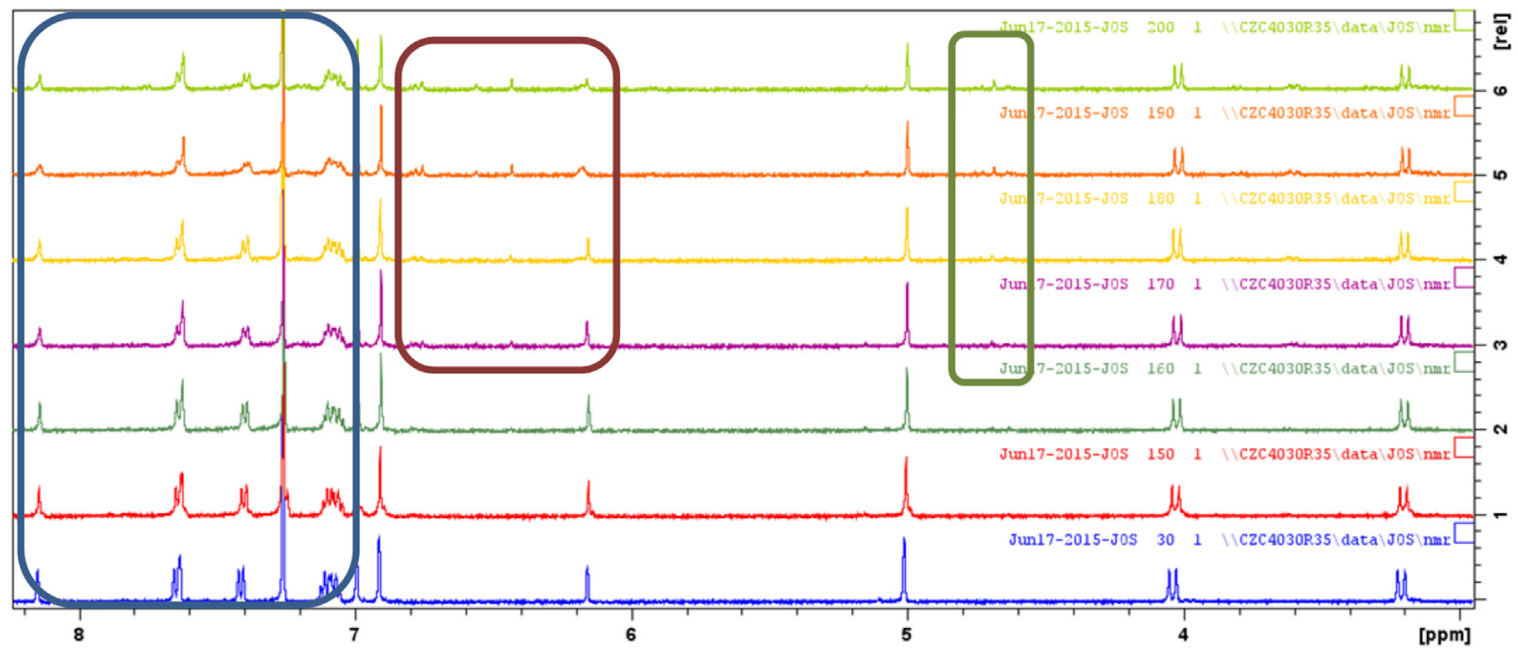

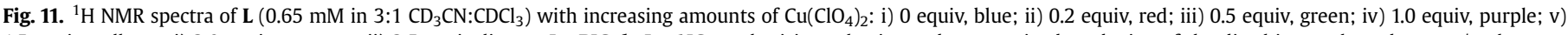

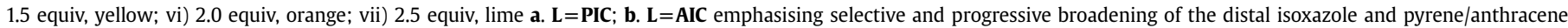
resonances (blue box) and additional new signals in the isoxazole and Calixarene $\mathrm{Ar}-\mathrm{H}$ region (red box) and in the $\mathrm{ArOCH}_{2}$ region (green box).

and zinc perchlorate, chosen as being representative of those salts which either caused quenching [copper(II)] or showed no effect [zinc(II)] on the fluorescence of the ligand, were followed by ${ }^{1} \mathrm{H}$ NMR spectroscopy recorded in the presence of up to 2.5 equiv of metal salt; $\mathrm{CD}_{3} \mathrm{CN} / \mathrm{CDCl}_{3}$ (3:1) was selected as the solvent mix to best mimic the conditions of the fluorescence study. In spite of a slight, non-specific broadening of the signals of PIC, no perceptible change was observed in either resonance position or signal appearance for any of the protons of PIM or the calix[4]arene ligands PIC and AIC in the presence of zinc perchlorate (Supplementary data Figs. 26-28). In contrast, significant site specific, and concentration dependant metal induced changes are evident in the ${ }^{1} \mathrm{H}$ NMR spectra of the model compound and the calixarenes following exposure to copper(II) perchlorate. The spectra of PIM indicate instantaneous, and progressive, broadening of the pyrene resonances in the presence of the guest. More subtle broadening and a slight downfield shift of the isoxazole proton signal was also observed. Even following titration of 2 equiv of the copper salt, no perceptible changes to the resonance or the resolution of the signals of the remaining protons of PIM were noted (Supplementary data Fig. 29). Non-covalent copper(II) $-\pi$ interactions, on a par with $\mathrm{H}$-bonding and salt bridge formation, are known with tryptophan residues ${ }^{52}$ and with hydrophobic protein cavities. ${ }^{53}$ They are also exploited as key design features in catalysts $^{54}$ and cyclophane cation sensing compounds. ${ }^{55}$ Favourable cation $-\pi$ interactions are also responsible for methyl viologen recognition by bisisoxazolylanthryl biscalix[4]arenes. ${ }^{56}$ Whilst not visible by spectrofluorometric analysis, the non-uniform response of the PIM protons to copper(II) ions strongly suggests a binding event engaging the pyrene and isoxazole modules but not involving the $t-\mathrm{BuAr}-\mathrm{CH}_{2}$ region.

In spite of the bulk paramagnetism of the solution, the ${ }^{1} \mathrm{H}$ NMR spectra recorded for the titration of PIC and AIC with up to 2.5 equiv of copper(II) perchlorate remain remarkably structured [Supplementary data Figs. 30 and 31]. In each case, following addition of the copper salt, the samples, in $\mathrm{CD}_{3} \mathrm{CN} / \mathrm{CDCl}_{3}$ (3:1), were left to equilibrate for $20 \mathrm{~min}$ prior to the recording of spectroscopic data. As anticipated, the metal induced changes observed with PIC essentially mirrored those observed for AIC. The dominant features of the titrated samples are a selective and progressive broadening of the distal isoxazole and pyrene/anthracene resonances against a backdrop where all other protons signals remain rather well 
resolved. A number of additional signals with progressively increasing relative intensities were observed including two singlets downfield of the host $t$-Bu resonances and one singlet $\sim 0.2 \mathrm{ppm}$ upfield of the respective $\mathrm{OCH}_{2}$ resonances of the hosts. Further new resonances between $\sim 6.0$ and $7.0 \mathrm{ppm}$ are attributed to the isoxazole and the core calixarene $\mathrm{Ar}-\mathrm{H}$ of the host-guest complex. A signal, $\sim 0.28 \mathrm{ppm}$ upfield of the isoxazole proton of PIC is noted in the presence of the guest whilst association of copper(II) with AIC causes the emergence of a new signal downfield, by approximately the same magnitude, of the corresponding proton of the host. That the spectroscopic response of PIC to copper in MeCN was not simply due to the acidity of the copper ion was ruled out by control experiments which indicated no discernible change in the isoxazole ${ }^{1} \mathrm{H}$ NMR resonance upon exposure of PIC to perchloric acid [Supplementary data Fig. 32a], neither did the addition of acid effect the fluorescence emission of PIC [Supplementary data Fig. 32b]. The NMR data thus supports a simple scaffolding role for the calix[4] arene core with complex formation involving, to varying extents, an ionic association between the cation and the heterocyclic nuclei, and/or a copper(II) $-\pi$ interaction with the polycyclic hydrocarbon rings. Analysis of the Job plot clearly proposed 1:1 binding stoichiometry and the possibility for on/off guest binding on the NMR timescale could not be resolved by ${ }^{1} \mathrm{H}$ NMR spectroscopic investigation at reduced temperature due to limitations of ligand solubility.

The similarity in size of the divalent ions makes it difficult to reconcile the anomalous sensitivity of PIC and AIC towards copper(II) ions over a range of other metal(II) perchlorates investigated in this work. Isoxazole nuclei are capable of $\mathrm{N}$ - and $\mathrm{O}$-centred coordination to a diverse range of metal ions ${ }^{57}$ and at the outset we postulated guest ion encapsulation involving coordination to the heterocycle and the lower rim phenolic $\mathrm{OH}$ moieties. However, the experimental data can not definitively identify the coordination sites of the host. It may be the case that the sensitivity towards copper(II) ions arises from its privileged potential of to form a wider variety of geometrical complexes than most other divalent transition metal ions. ${ }^{58}$ In the absence of copper(II)/L crystals suitable for $\mathrm{X}$-ray analysis, we performed a series of hybrid Density Functional Theory (DFT) calculations to help understand if the specificity of PIC for copper(II) ions can be explained in terms of a preferential coordination geometry.

\subsection{Computational study}

Optimised (minimum energy) structures obtained for unbound PIC and its copper(II) complexes are shown in Fig. 12. The gas-phase minimum found for the host shows a distinctive intramolecular $\pi-\pi$ stacking between the two pyrenyl moieties, consistent with the observed broad excimer emission band. Two strategies were followed for the identification of the minimum structure of the complex. One strategy involved searching for a copper(II)/PIC complex structure without the participation of coordinating solvent molecules while the second strategy consisted of the search for a stable coordination sphere that includes solvent molecules, that is a copper(II)/PIC/MeCN complex. The minimum found for the copper(II)/PIC complex, (Fig. 12b), shows the metal ion having penta-coordinate, distorted square-pyramidal geometry, with one of the two isoxazole $\mathrm{O}$ atoms acting as the apical ligand (see Supplementary data Table 2). The base of the pyramid comprises the two hydroxyl groups from the calix[4]arene rim and the two ether $\mathrm{O}$ atoms between the calix[4]arene and the isoxazole. The geometric constraints imposed by the coordination sites of the host could be the basis for the selectivity of PIC towards copper(II) ions. Thus, whilst, square-pyramidal penta-coordinate complexes of copper(II) ions involving both $\mathrm{N}$ and $\mathrm{O}$ donor atoms are known, ${ }^{59-61}$ such coordination to the other divalent metal ions tested in this work may not be attractive enough to compensate for the energy demands of desolvation and the breaking of the pyrene/ pyrene $\pi-\pi$ stacking. The suggested structure involves the isoxazole $\mathrm{O}$-atom in the metal coordination, which induces significant rotation of the pyrenyl moieties relative to their orientation in the unbound PIC (Fig. 12a, b). This in turn causes disruption of the $\pi-\pi$ stacking, consistent with the experimentally observed excimer quenching. ${ }^{48}$ However, this structure is a poor fit with the ${ }^{1} \mathrm{H}$ NMR data which suggests the complexed copper(II) has a minimal influence on the lower rim phenolic $\mathrm{OH}$ groups and a more significant effect on the isoxazole proton and the pendant aryl rings. Thus, attempts were made to find a 1:1 $\pi$-cation interaction between the copper(II) ion and the pyrene rings of the PIC. All calculations failed indicating that such an interaction, if it does exist, is not sufficiently stable in the gas-phase. Finally, we searched for a copper(II)/PIC complex involving solvent, the inclusion of two $\mathrm{MeCN}$ molecules in the coordination sphere allowed for the localisation of a tetrahedral copper(II)/PIC/MeCN complex, shown in Fig. 12c. The structure invokes only the isoxazole nitrogen atoms and two MeCN molecules in the coordination sphere. The conformational changes associated with this structure include disruption of the $\pi-\pi$ stacking characteristic of the parent and, importantly, coordination through the heterocyclic $N$-atoms and residence of the guest in the proximity of the pyrene rings is consistent with the most significant effects of the NMR study of the copper(II)/L titration experiments being experienced at the isoxazole and pyrene/anthracene moieties. This model, with two MeCN ligands, also allies with the a

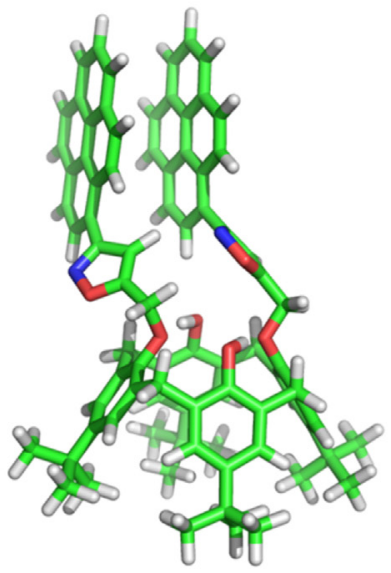

b

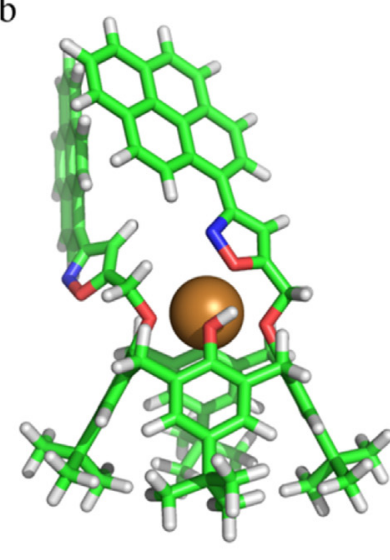

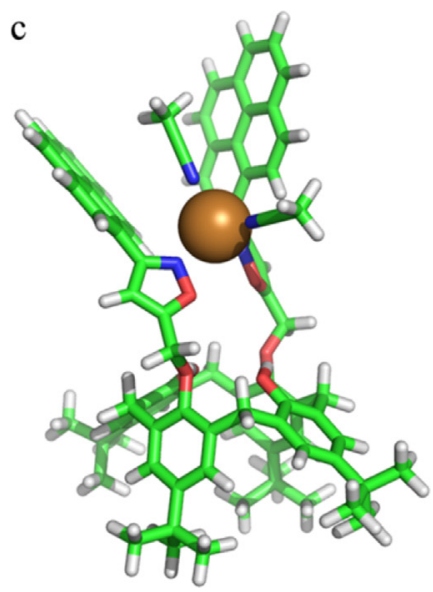

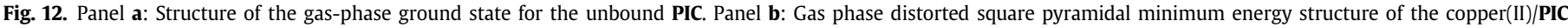
complex, Panel c: Tetrahedrally coordinated minimum energy structure of the copper(II)/PIC in solution, where two solvent molecules complete the coordination sphere. 
observed failure of PIC to respond spectrofluorometrically to copper(II) perchlorate in EtOH or in $\mathrm{MeOH} / \mathrm{CHCl}_{3}$ (96:4) (Supplementary data Fig. 20a, b). The sensitivity of these type of calix[4]arene framed chemosensors with a conjugated heterocyclefluorophore unit is indeed remarkable. Thus, a sensor with distal conjugated triazolylpyrenes exhibits selectivity for silver(I) ions in $\mathrm{MeOH} / \mathrm{CHCl}_{3}(98: 2)^{17}$ whilst PIC shows no spectrofluorometric response under the same conditions (Supplementary data Fig. 20c).

\section{Conclusions}

A new calix[4]arene fluorogenic sensor equipped with distal isoxazole rings as potential cation binding sites and anthracene or pyrene units as aryl fluorophores has been synthesised by catalystfree nitrile oxide alkyne cycloaddition chemistry. The X-ray structure indicates solid state packing involves $\pi$-stacking between the pyrene/anthracene rings in neighbouring molecules, however, excimer fluorescence emission is in keeping with an intramolecular interaction of the pendant aryl units in the solution phase. Chelation enhanced fluorescence quenching (CEFQ) is observed upon ligand binding of only copper(II) ions within a range of transition metal perchlorates. Spectroscopic data concurs with a structural role for calix[4]arene, facilitating an optimal alignment of coordination and reporting modules for the selective detection of copper(II) ions (with perchlorate anions) in $\mathrm{MeCN}$. The hypothesis that the isoxazole nucleus functions as a copper(II) binding site facilitating excimer quenching through cation $-\pi$ interaction is in keeping with a minimised tetrahedral copper(II)/PIC/(MeCN $)_{2}$ structure found by DFT calculations. It is clear that the selectivity of these type of chemosensors can be refined by the appropriate combination of solvent and counter-anions as well as by choice of coordinating heterocycle (isoxazole or triazole) and by the design to build conjugation, or not, between the heterocycle and the reporting pyrene.

\section{Experimental}

\subsection{General}

${ }^{1} \mathrm{H}$ and ${ }^{13} \mathrm{C}$ NMR $(\delta \mathrm{ppm} ; J \mathrm{~Hz})$ spectra were recorded on either a Bruker Avance $300 \mathrm{MHz}$ NMR spectrometer or a Bruker Avance $500 \mathrm{MHz}$ spectrometer as $\mathrm{CDCl}_{3}$ solutions with $\mathrm{Me}_{4} \mathrm{Si}$ as reference, unless indicated otherwise. Infrared spectra $\left(\mathrm{cm}^{-1}\right)$ were recorded as $\mathrm{KBr}$ discs using a Perkin Elmer System 2000 FT-IR spectrometer. UV-vis spectra were recorded in the indicated solvents using a Unicam UV 540 spectrometer. Fluorescence spectra, in emission mode, were recorded using a Jasco FP6300 fluorescence spectrophotometer. Stock solutions in HPLC grade MeCN of free ligand $(12.0 \mu \mathrm{M})$ and metal salt $(1200 \mu \mathrm{M}$ in water) were prepared. All measurements were made using $3000 \mu \mathrm{L}$ quartz cells. EPR spectra were recorded on a Bruker Elexsys E500 spectrometer, operated at the X-band and equipped with an Oxford Instruments cryostat. Melting point analyses were carried out using a Stewart Scientific SMP 1 melting point apparatus and are uncorrected. Electrospray (ESI) mass spectra were collected on an Agilent Technologies 6410 Time of Flight LC/MS. Compounds were dissolved in acetonitrile-water (1:1) solutions containing $0.1 \%$ formic acid, unless otherwise stated. The interpretation of mass spectra was made with the help of the program 'Agilent Masshunter Workstation Software'. As appropriate, commercially available starting materials were used without further purification.

Caution! Although not encountered in our experiments, perchlorate salts of metal ions are potentially explosive and should be manipulated with care and used only in small quantities.

\subsection{5-((4-tert-Butylphenoxy)methyl)-3-(pyren-6-yl)isoxazole (PIM)}

To a solution of the propargyl ether $1(0.20 \mathrm{~g}, 1.06 \mathrm{mmol})$ in EtOH ( $30 \mathrm{~mL})$ was added 1-pyrene carboxaldehyde oxime $2(0.13 \mathrm{~g}$, $0.53 \mathrm{mmol})$ and chloramine-T $(0.12 \mathrm{~g}, 0.53 \mathrm{mmol})$. The mixture was heated at reflux and reaction progress was followed by TLC $\left(\mathrm{SiO}_{2}\right.$, DCM:MeOH, 100:1). After a $2 \mathrm{~h}$ interval, a second portion of oxime and of chloramine-T ( $0.53 \mathrm{mmol}$ each) was added. Heating at reflux was continued for another $2 \mathrm{~h}$ interval prior to the addition of a third portion of oxime and chloramine-T ( $0.53 \mathrm{mmol}$ each $)$. The reaction was terminated after a total of 6 h heating. Water $(50 \mathrm{~mL})$ was added. The mixture was extracted with chloroform $(15 \mathrm{~mL} \times 3)$. The organic layers were combined, washed with $5 \% \mathrm{NaOH}$ $(10 \mathrm{~mL} \times 3)$ and dried over anhydrous $\mathrm{MgSO}_{4}$. The solvent was removed by evaporation under reduced pressure. The crude product was purified by flash column chromatography $\left(\mathrm{SiO}_{2}, \mathrm{DCM}: \mathrm{MeOH}\right.$, $100: 1)$. The desired product was obtained as a yellow solid $(0.29 \mathrm{~g}$, 62\%); mp 142-152 ${ }^{\circ} \mathrm{C} ;{ }^{1} \mathrm{H}$ NMR (300 MHz, $\left.\mathrm{CDCl}_{3}\right) \delta 1.32(\mathrm{~s}, 9 \mathrm{H}$, $\left.\mathrm{C}\left(\mathrm{CH}_{3}\right)_{3}\right), 5.31\left(\mathrm{~s}, 2 \mathrm{H}, \mathrm{OCH}_{2}\right), 6.82(\mathrm{~s}, 1 \mathrm{H}$, isoxazole $\mathrm{CH}), 7.00(\mathrm{~d}$, $J=9.1 \mathrm{~Hz}, 2 \mathrm{H}, \mathrm{ArH}), 7.37$ (d, $J=9.3 \mathrm{~Hz}, 2 \mathrm{H}, \mathrm{ArH}), 8.26-8.05(\mathrm{~m}, 8 \mathrm{H}$, ArH), 8.67 (d, $J=9.6 \mathrm{~Hz}, 1 \mathrm{H}, \mathrm{ArH}) ;{ }^{13} \mathrm{C} \mathrm{NMR}\left(75 \mathrm{MHz}, \mathrm{CDCl}_{3}\right) \delta 31.5$, $34.2,61.7,105.1,114.3,123.4,124.5,124.7,124.8,125.6,125.8,126.3$, $126.5,127.2,128.5,128.7,130.7,131.2,132.3,144.7,155.6,163.1$, 168.3; IR( $\left(\mathrm{cm}^{-1}\right)$ 2863, 1603, 1510, 1185, 849, 827; ESI-HRMS $\mathrm{m} / \mathrm{z}$ $[\mathrm{M}+\mathrm{H}]^{+}$calcd for $\mathrm{C}_{30} \mathrm{H}_{26} \mathrm{NO}_{2}$ 432.1958. Found 432.1976.

\subsection{3-(Anthracen-10-yl)-5-((4-tert-butylphenoxy)methyl)iso- xazole (AIM)}

To a solution of the propargyl ether $\mathbf{1}(0.25 \mathrm{~g}, 1.35 \mathrm{mmol})$ in EtOH $(40 \mathrm{~mL})$ was added 9-anthracene carboxaldehyde oxime $3(0.15 \mathrm{~g}$, $0.68 \mathrm{mmol}$ ) and chloramine-T $(0.15 \mathrm{~g}, 0.66 \mathrm{mmol})$. The mixture was heated at reflux and reaction progress was followed by $\operatorname{TLC}\left(\mathrm{SiO}_{2}\right.$, DCM:petroleum ether, 1:2). After a $2 \mathrm{~h}$ interval a second portion of oxime and of chloramine- $\mathrm{T}$ ( $0.68 \mathrm{mmol}$ each $)$ was added. Heating at reflux was continued for another $2 \mathrm{~h}$ interval prior to the addition of a third portion of oxime and chloramine-T ( $0.68 \mathrm{mmol}$ each). The reaction was terminated after a total of $6 \mathrm{~h}$ heating. Water $(100 \mathrm{~mL})$ was added. The mixture was extracted with chloroform $(15 \mathrm{~mL} \times 3)$. The organic layers were combined, washed with $5 \% \mathrm{NaOH}$ $(15 \mathrm{~mL} \times 3)$ and dried over anhydrous $\mathrm{MgSO}_{4}$. The solvent was removed by evaporation under reduced pressure. The crude product was purified by flash column chromatography $\left(\mathrm{SiO}_{2}\right.$, DCM:petroleum ether, $\left.1: 2, R_{f}=0.4\right)$. The desired product was obtained as a yellow liquid $(0.27 \mathrm{~g}, 98 \%) ;{ }^{1} \mathrm{H} \mathrm{NMR}\left(300 \mathrm{MHz}, \mathrm{CDCl}_{3}\right) \delta 1.32(\mathrm{~s}, 9 \mathrm{H}$, $\left.\mathrm{C}\left(\mathrm{CH}_{3}\right)_{3}\right), 5.38\left(\mathrm{~s}, 2 \mathrm{H}, \mathrm{OCH}_{2}\right), 6.61(\mathrm{~s}, 1 \mathrm{H}$, isoxazole $\mathrm{CH}), 7.01-6.97$ $(\mathrm{m}, 2 \mathrm{H}, \mathrm{ArH}), 7.39-7.34(\mathrm{~m}, 2 \mathrm{H}, \mathrm{ArH}), 7.52-7.42(\mathrm{~m}, 4 \mathrm{H}, \mathrm{ArH})$, $7.87-7.83(\mathrm{~m}, 2 \mathrm{H}, \mathrm{ArH}), 8.06$ (dd, $J=7.2 \& 1.8 \mathrm{~Hz}, 2 \mathrm{H}, \mathrm{ArH}), 8.58(\mathrm{~s}$, $1 \mathrm{H}, \mathrm{ArH}) ;{ }^{13} \mathrm{C}$ NMR $\left(75 \mathrm{MHz}, \mathrm{CDCl}_{3}\right) \delta 31.5,34.2,61.8,106.9,114.5$, 122.9, 125.4, 125.6, 126.5, 126.6, 128.5, 129.1, 130.6, 131.2, 144.8, 155.7, 161.0, 167.7; IR( $\left.\mathrm{cm}^{-1}\right)$ 2962, 1605, 1512, 1363, 1232, 998, 893, 732; ESI-HRMS $m / z[2 \mathrm{M}+\mathrm{Na}]^{+}$calcd for $\mathrm{C}_{56} \mathrm{H}_{50} \mathrm{~N}_{2} \mathrm{NaO}_{4}$ 837.3663, found 837.3681 .

\subsection{3-(Pyrenen-1-yl)-(4-tert-butylcalix[4]arene)isoxazole (PIC)}

The propargylated calix[4]arene $4(0.26 \mathrm{~g}, 0.37 \mathrm{mmol})$ was added to a mixture of pyrene 1-carboxaldehyde oxime $\mathbf{2}(0.37 \mathrm{~g}$, $1.50 \mathrm{mmol})$ and chloramine-T $(0.42 \mathrm{~g}, 1.85 \mathrm{mmol})$ in EtOH $(30 \mathrm{~mL})$. The mixture was heated at reflux and reaction progress was followed by TLC $\left(\mathrm{SiO}_{2}\right.$, DCM:petroleum ether:MeOH=1:1:0.01). The reaction was terminated after $18 \mathrm{~h}$ heating. Water $(30 \mathrm{~mL})$ was added. The mixture was extracted with chloroform $(10 \mathrm{~mL} \times 3)$. The organic layers were combined, washed with $5 \% \mathrm{NaOH}(10 \mathrm{~mL} \times 2)$ 
and dried over anhydrous $\mathrm{MgSO}_{4}$. The solvent was removed by evaporation under reduced pressure. The crude product was purified by flash column chromatography ( $\left.\mathrm{SiO}_{2}, \mathrm{DCM}: \mathrm{MeOH}, 100: 1\right)$. The appropriate fractions were combined and the product, following crystallisation from DCM/petroleum ether (1:2), was obtained as a white solid (0.24 g, 54\%); mp 208-222 ${ }^{\circ} \mathrm{C} ;{ }^{1} \mathrm{H}$ NMR $\left(300 \mathrm{MHz}, \mathrm{CDCl}_{3}\right) \delta 0.97\left(\mathrm{~s}, 18 \mathrm{H}, \mathrm{C}\left(\mathrm{CH}_{3}\right)_{3}\right), 1.31\left(\mathrm{~s}, 18 \mathrm{H}, \mathrm{C}\left(\mathrm{CH}_{3}\right)_{3}\right), 3.40$ (d, $\left.J=13.2 \mathrm{~Hz}, 4 \mathrm{H}, \mathrm{CH}_{2}\right), 4.37$ (d, $\left.J=13.2 \mathrm{~Hz}, 4 \mathrm{H}, \mathrm{CH}_{2}\right), 5.29$ (s, $4 \mathrm{H}$, $\left.\mathrm{OCH}_{2}\right), 6.84(\mathrm{~s}, 4 \mathrm{H}, \mathrm{ArH}), 6.88(\mathrm{~s}, 2 \mathrm{H}, \mathrm{OH}), 6.97(\mathrm{~s}, 2 \mathrm{H}$, isoxazole $\mathrm{CH})$, 7.11 (s, 4H, ArH), 7.76 (d, J=9.0 Hz, 2H, ArH), 7.97-7.88 (m, 10H, ArH), $8.07(\mathrm{~m}, 4 \mathrm{H}, \mathrm{ArH}), 8.54(\mathrm{~d}, J=9.3 \mathrm{~Hz}, 2 \mathrm{H}, \operatorname{ArH}) ;{ }^{13} \mathrm{C}$ NMR $\left(75 \mathrm{MHz}, \mathrm{CDCl}_{3}\right) \delta 31.0,31.7,33.9,34.0,68.5,105.4,122.9,124.2$, $124.6,124.8,125.2,125.3,125.5,125.9,126.0,127.0,127.8,128.1$, 128.7, 131.0, 132.0, 132.4, 142.0, 147.8, 149.6, 150.5, 163.1, 167.6; IR $\left(\mathrm{cm}^{-1}\right)$ 3429, 2960, 1603, 1485, 1363, 1190, 846; ESI-HRMS m/z $[\mathrm{M}+\mathrm{H}]^{+}$calcd for $\mathrm{C}_{84} \mathrm{H}_{79} \mathrm{~N}_{2} \mathrm{O}_{6}$ 1211.5933, found 1211.5959 .

\subsection{3-(Anthracen-10-yl)-(4-tert-butylcalix[4] arene)isoxazole (AIC)}

The propargylated calix[4]arene $4(0.30 \mathrm{~g}, 0.43 \mathrm{mmol})$ was added to a mixture of anthracene 9-carboxaldehyde oxime $\mathbf{3}$ $(0.19 \mathrm{~g}, 0.75 \mathrm{mmol})$ and chloramine-T $(0.20 \mathrm{~g}, 0.90 \mathrm{mmol})$ in EtOH $(60 \mathrm{~mL})$. The mixture was heated at reflux and reaction progress was followed by TLC $\left(\mathrm{SiO}_{2}, \mathrm{DCM}\right.$ :petroleum ether:$\mathrm{MeOH}=1: 1: 0.01)$. After a $3 \mathrm{~h}$ interval, a second portion of oxime $(0.19 \mathrm{~g})$ and of chloramine-T $(0.20 \mathrm{~g})$ was added. Heating at reflux was continued for a further $16 \mathrm{~h}$. Water $(30 \mathrm{~mL})$ was added. The mixture was extracted with chloroform $(10 \mathrm{~mL} \times 3)$. The organic layers were combined, washed with $5 \% \mathrm{NaOH}(10 \mathrm{~mL} \times 2)$ and dried over anhydrous $\mathrm{MgSO}_{4}$. The solvent was removed by evaporation under reduced pressure. The crude product was purified by flash column chromatography $\left(\mathrm{SiO}_{2}\right.$, petroleum ether:ethyl acetate, $\left.3: 1\right)$. The appropriate fractions were combined and the product, following crystallisation from petroleum ether:ethyl acetate (3:1), was obtained as a white solid $(0.25 \mathrm{~g}, 51 \%) ; \mathrm{mp} 174-190{ }^{\circ} \mathrm{C} ;{ }^{1} \mathrm{H}$ NMR (300 MHz, $\left.\mathrm{CDCl}_{3}\right) \delta 0.94\left(\mathrm{~s}, 18 \mathrm{H}, \mathrm{C}\left(\mathrm{CH}_{3}\right)_{3}\right), 1.31(\mathrm{~s}, 18 \mathrm{H}$, $\left.\mathrm{C}\left(\mathrm{CH}_{3}\right)_{3}\right), 3.37\left(\mathrm{~d}, J=13.2 \mathrm{~Hz}, 4 \mathrm{H}, \mathrm{CH}_{2}\right), 4.29\left(\mathrm{~d}, J=13.2 \mathrm{~Hz}, 4 \mathrm{H}, \mathrm{CH}_{2}\right)$, $5.27\left(\mathrm{~s}, 4 \mathrm{H}, \mathrm{OCH}_{2}\right), 6.48(\mathrm{~s}, 2 \mathrm{H}$, isoxazole $\mathrm{CH}), 6.70(\mathrm{~s}, 2 \mathrm{H}, \mathrm{OH}), 6.80$ (s, 4H, ArH), 7.09 (s, 4H, ArH), 7.43-7.33 (m, 8H, ArH), 7.79 (d, $J=7.8 \mathrm{~Hz}, 4 \mathrm{H}, \mathrm{ArH}), 7.93$ (d, $J=7.8 \mathrm{~Hz}, 4 \mathrm{H}, \operatorname{ArH}), 8.43(\mathrm{~s}, 2 \mathrm{H}, \operatorname{ArH}) ;{ }^{13} \mathrm{C}$ $\operatorname{NMR}\left(75 \mathrm{MHz}, \mathrm{CDCl}_{3}\right) \delta 31.0,31.7,33.9,34.0,67.7,108.1,125.2,125.3$, 125.6, 125.8, 126.5, 127.8, 128.4, 129.0, 130.6, 131.1, 132.5, 141.9, 147.7, 149.6, 150.4, 161.0, 167.9; IR( $\left.\mathrm{cm}^{-1}\right)$ 3448, 2960, 1626, 1484, 1363, 1207, 888, 735; ESI-HRMS $m / z[\mathrm{M}+\mathrm{Na}]^{+}$calcd for $\mathrm{C}_{80} \mathrm{H}_{78} \mathrm{~N}_{2} \mathrm{NaO}_{6}$ 1185.5752 , found 1185.5670 .

\subsection{X-ray structure determination}

Single crystal X-ray data collection, data reduction, ${ }^{62}$ structure solution and refinement ${ }^{63,64}$ protocols are as described previously. ${ }^{65,66}$ Molecular diagrams (Fig. 3 and Supplementary data Fig. 14) were generated using Mercury ${ }^{67}$ as ball and stick diagrams or with atoms as their van der Waals spheres. CCDC reference codes 1428623-1428624 and copies available, email:deposit@ccdc.cam.ac.uk.

\subsection{Computational method}

The PIC ground state structure in the absence of copper(II) was obtained by geometry optimisation in terms of redundant internal coordinates with the quasi-Newton Raphson (qNR) algorithm. This geometry optimisation was started from the calix[4]arene crystal structure of the monomer, shown in Fig. 12. The calculation was performed at the RI-B97D//def2-TZVP level of theory, where the B97 functional was augmented with Grimme dispersion correction. $^{68}$ The SCF convergency criterion was set at $10^{-6}$ au and the gradient convergence threshold was set at $10^{-3} \mathrm{au}$. One of the copper(II)/PIC complex minimum structure was determined based on the geometry optimisation of unbiased conformations generated by placing the copper(II) ion at six different positions along the $y$-axis within the calix[4] arene crown, with distances between the ion and one of the $\mathrm{N}$ of the isoxazole between $9.0 \AA$ and $3.0 \AA$ in $1 \AA$ steps. This geometry optimisation was started from the minimum structure of the metal-free calix[4]arene. The geometry optimization of the copper(II)/PIC complexes was run in two steps: 1) Berny algorithm at the ROHF//6-31G* level, with the ion restrained and the PIC free, 2) qNR at the UB3LYP//defSV(P) with all atoms free. Further refinement with functionals augmented by a dispersion contribution, such as B97D, B3LYPD and M06-2X, did not converge. The starting structure for the search of a tetrahedral coordinated minimal was built with the academic version of Schrodinger Maestro, ${ }^{69}$ starting from the square pyramidal minimum by changing the position of the copper(II) ion and the relative distances with the isoxazoles. All calculations discussed in this study have been performed with version 6.0 of Turbomole. ${ }^{70}$

\section{Acknowledgements}

We acknowledge Dr. John F. Gallagher for his work on the X-ray crystal structure. N.M. thanks South Dublin County Council and J.O.S. acknowledges an IRC EMBARK Scholarship (RS/2012/128) for provision of financial assistance.

\section{Supplementary data}

Supplementary data associated with this article can be found in the online version, at http://dx.doi.org/10.1016/j.tet.2015.10.045.

\section{References and notes}

1. Kim, J. S.; Quang, D. T. Chem. Rev. 2007, 107, 3780

2. Lo, P. K.; Wong, M. S. Sensors 2008, 8, 5313.

3. Creaven, B. S.; Donlon, D. F.; McGinley, J. Coord. Chem. Rev. 2009, 253, 893.

4. Joseph, R.; Rao, C. P. Chem. Rev. 2011, 111, 4658.

5. Mahon, M. F.; McGinley, J.; Rooney, A. D.; Walsh, J. M. D. Tetrahedron 2008, 64, 11058.

6. McGinley, J.; Walsh, J. M. D. Inorg. Chem. Commun. 2011, 14, 1018.

7. McGinley, J.; McKee, V.; Walsh, J. M. D. Inorg. Chim. Acta 2011, 375, 57.

8. Kolb, H. C.; Finn, M. G.; Sharpless, K. B. Angew. Chem., Int. Ed. 2001, 40, 2005.

9. Tornøe, C. W.; Christensen, C.; Meldal, M. J. Org. Chem. 2002, 67, 3057.

10. Souchon, V.; Leray, I.; Berberan-Santos, M. N.; Valeur, B. Dalton Trans. 2009 3988.

11. Tian, D.; Yan, H.; Li, H. Supramol. Chem. 2010, 22, 249.

12. Pathak, R. K.; Dikundwar, A. G.; Row, T. N. G.; Rao, C. P. Chem. Commun. 2010, 4345.

13. Pathak, R. K.; Hinge, V. K.; Mondal, M.; Rao, C. P. J. Org. Chem. 2011, 76, 10039. 14. Pathak, R. K.; Tabbasum, K.; Hinge, V. K.; Rao, C. P. Chem.-Eur. J. 2011, 17, 13999. 15. Zhan, J.; Fang, F.; Tian, D.; Li, H. Supramol. Chem. 2012, 24, 272.

16. Pathak, R. K.; Hinge, V. K.; Rai, A.; Panda, D.; Rao, C. P. Inorg. Chem. 2012, 51 , 4994.

17. Wang, N.-J.; Sun, C.-M.; Chung, W.-S. Sens. Actuators, B 2012, 171-172, 984.

18. Pathak, R. K.; Hinge, V. K.; Mondal, P.; Rao, C. P. Dalton Trans. 2012, 41, 10652.

19. de Silva, A. P.; Fox, D. B.; Huxley, A. J. M.; Moody, T. S. Coord. Chem. Rev. 2000, 205, 41.

20. He, G.; Zhang, X.; He, C.; Zhao, X.; Duan, C. Tetrahedron 2010, 66, 9762.

21. Que, E. L.; Domaille, D. W.; Chang, C. J. Chem. Rev. 2008, 108, 1517.

22. Chawla, H. M.; Goel, P.; Shukla, R. Tetrahedron Lett. 2013, 54, 2766.

23. Kunthadee, P.; Watchasit, S.; Kaowliew, A.; Suksai, C.; Wongsan, W.; Ngeontae W.; Chailapakul, O.; Aeungmaitrepirom, W.; Tuntulani, T. New J. Chem. 2013, 37, 4010.

24. Sahin, O.; Akceylan, E. Tetrahedron 2014, 70, 6944.

25. Algay, V.; Singh, I.; Heaney, F. Org. Biomol. Chem. 2010, 8, 391.

26. Singh, I.; Vyle, J.; Heaney, F. Chem. Commun. 2009, 3276.

27. Heaney, F. Eur. J. Org. Chem. 2012, 3043.

28. Ho, I.-T.; Haung, K.-C.; Chung, W.-S. Chem.-Asian J. 2011, 6, 2738.

29. Park, S. Y.; Yoon, J. H.; Hong, C. S.; Souane, R.; Kim, J. S.; Matthews, S. E.; Vicens, J. J. Org. Chem. 2008, 73, 8212.

30. Kim, J. S.; Park, S. Y.; Kim, S. H.; Thuéry, P.; Souane, R.; Matthews, S. E.; Vicens, J. Bull. Korean Chem. Soc. 2010, 31, 624. 
31. Asfari, Z.; Bilyk, A.; Bond, C.; Harrowfield, J.; Koutsantonis, G. A.; Lengkeek, N.; Mocerino, M.; Skelton, B. W.; Sobolev, A. N.; Strano, S.; Vicens, J.; White, A. H. Org. Biomol. Chem. 2004, 2, 387.

32. Hassner, A.; Rai, K. M. L. Synthesis 1989, 57.

33. Chang, K.-C.; Luo, L.-Y.; Diau, E. W.-G.; Chung, W.-S. Tetrahedron Lett. 2008, 49, 5013.

34. Himo, F.; Lovell, T.; Hilgraf, R.; Rostovtsev, V. V.; Noodleman, L.; Sharpless, K. B.; Fokin, V. V. J. Am. Chem. Soc. 2005, 127, 210.

35. Grecian, S.; Fokin, V. V. Angew. Chem., Int. Ed. 2008, 47, 8285.

36. Gutsche, C. D. Calixarenes: An Introduction, 2nd ed.; Royal Society of Chemistry: Cambridge, UK, 2008.

37. Fischer, C.; Gruber, T.; Eissmann, D.; Seichter, W.; Weber, E. Cryst. Growth Des. 2011, 11, 1989.

38. Suwinska, K.; Shkurenko, O.; Mbemba, C.; Leydier, A.; Jebors, S.; Coleman, A. W.; Matar, R.; Falson, P. New J. Chem. 2008, 32, 1988.

39. De Araujo, A. S.; Piro, O. E.; Castellano, E. E.; De Namor, A. F. D. J. Phys. Chem. A 2008, 112, 11885.

40. Bocheńska, M.; Zielińska, A.; Kravtsov, V. C.; Gdaniec, M.; Luks, E.; RadeckaParyzek, W. Polyhedron 2002, 21, 763.

41. Böhmer, V.; Ferguson, G.; Gallagher, J. F.; Lough, A. J.; McKervey, M. A.; Madigan, E.; Moran, M. B.; Phillips, J.; Williams, G. J. B. J. Chem. Soc., Perkin Trans. 1 1993, 1521.

42. Bond, A. D.; Creaven, B. S.; Donlon, D. F.; Gernon, T. L.; McGinley, J.; Toftlund, H. Eur. J. Inorg. Chem. 2007, 749.

43. Gruber, T.; Seichter, W.; Weber, E. Supramol. Chem. 2008, 20, 753.

44. Mummidivarapu, V. V. S.; Hinge, V. K.; Tabbasum, K.; Gonnade, R. G.; Rao, C. P.J. Org. Chem. 2013, 78, 3570

45. Broan, C. J. Chem. Commun. 1996, 699.

46. Kim, S. K.; Kim, S. H.; Kim, H. J.; Lee, S. H.; Lee, S. W.; Ko, J.; Bartsch, R. A.; Kim, J. S. Inorg. Chem. 2005, 44, 7866.

47. Inamo, M.; Kohagura, T: Kaljurand, I; Leito, I. Inorg. Chim. Acta 2002, 340, 87.

48. Senthilvelan, A.; Ho, I.-T.; Chang, K.-C.; Lee, G.-H.; Liu, Y.-H.; Chung, W.-S. Chem. -Eur. J. 2009, 15, 6152.
49. Job, P. Ann. Chim. Appl. 1928, 18, 113

50. Goswami, S.; Chakraborty, S.; Paul, S.; Panja, S.; Mukhopadhvay, S. K. Org. Biol. Chem. 2014, 12, 3037.

51. Benesi, H. A.; Hildebrand, J. H. J. Am. Chem. Soc. 1949, 71, 2703.

52. Yorita, H.; Otoma, K.; Hiramatsu, H.; Toyama, A.; Miura, T.; Takeuchi, H. J. Am. Chem. Soc. 2008, 130, 15266.

53. Rundqvist, L.; Tengel, T.; Zdunek, J.; Björn, E.; Schleucher, J.; Alcocer, M. J.; Larsson, G. PLos One 2012, 7, e46435.

54. Ishihara, K.; Fushimi, M.; Akakura, M. Acc. Chem. Res. 2007, 40, 1049.

55. Bartoli, S.; Roelens, S. J. Am. Chem. Soc. 2002, 124, 8307.

56. Tsai, C.-C.; Ho, I.-T.; Chu, J.-H.; Shen, L.-C.; Huang, S.-L.; Chung, W.-S. J. Org. Chem. 2012, 77, 2254

57. Munsey, M. S. Natale, N. R. Coord Chem Rev. 1991, 109, 251.

58. Cotton, F. A.; Wilkinson, G.; Murillo, C. A.; Bochmann, M. Advanced Inorganic Chemistry: A Comprehensive Text, 6th ed.; Blackwell-Wiley, 1999; p 854.

59. Hasenknopf, B.; Lehn, J.-M.; Baum, G.; Fenske, D. Proc. Natl. Acad. Sci. U.S.A. 1996, 93, 1397.

60. Zhou, M.; Song, L.; Niu, F.; Shu, K.; Chai, W. Acta Crystallogr. 2013, C69, 463.

61. Vafazadeh, R.; Esteghamat-Panah, R.; Willis, A. C.; Hill, A. F. Polyhedron 2012, 48

62. Oxford Diffraction Ltd. ABSFAC and CrysAlisPro CCD/RED, Version 1.171.33.55, Oxford Diffraction, Abingdon, Oxfordshire, U.K.

63. Sheldrick, G. M. Acta Crystallogr., Sect. A 2008, A64, 11.

64. McArdle, P. J. Appl. Crystallogr. 1995, 28, 65.

65. Mocilac, P.; Tallon, M.; Lough, A. J.; Gallagher, J. F. CrystEngComm 2010, 12, 3080.

66. Mocilac, P.; Donnelly, K.; Gallagher, J. F. Acta Crystallogr. 2012, B68, 189.

67. Mercury; Cambridge Crystallographic Data Centre, 2015.

68. Grimme, S. J. Comput. Chem. 2006, 27, 1787.

69. Maestro, version 9.7, L. Schrödinger, 2014, New York, USA.

70. TURBOMOLE; GmbH, F. K., Ed.; University of Karlsruhe: Karlsruhe, Germany, 2012. 